\title{
Análise das Causas da Evasão na Educação a Distância em uma Instituição Federal de Ensino Superior
}

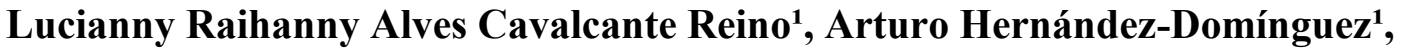 \\ Olival de Gusmão Freitas Júnior ${ }^{1}$, Victor Diogho Heuer Carvalho ${ }^{1}$, Petrucio \\ Antonio Medeiros Barros ${ }^{1}$, Marcus de Melo Braga ${ }^{1}$ \\ ${ }^{1}$ Instituto de Computação - Universidade Federal de Alagoas (UFAL) \\ Campus A. C. Simões - 57.072-970 - Maceió - AL - Brazil \\ rayejun@hotmail.com, arturohd@ic.ufal.br, olival@ic.ufal.br, \\ vdhceic.ufal.br, petrucio.barroseic.ufal.br, marcuseic.ufal.br
}

\begin{abstract}
This article presents an analysis of the main causes of students' dropping out of an undergraduate distance course in a Brazilian federal institution of higher education. The data were collected from the application of two questionnaires: one directed to dropout students and another to the remaining students. Responses were subsequently treated by means of basic statistics for the analysis and the final results. It was observed that the low incentive of teachers and tutors to the students, the difficulty of adaptation to the modality of distance education, and the short time of study dedicated to the course were the most important elements for failure and dropout.
\end{abstract}

Resumo. Este artigo apresenta uma análise das principais causas da evasão de alunos de um curso de graduação a distância em uma Instituição Federal de Ensino Superior brasileira. Os dados foram coletados a partir da aplicação de dois questionários: um direcionado aos alunos evadidos e outro aos alunos remanescentes. As respostas foram posteriormente tratadas por meio de estatísticas básicas, para a análise e obtenção dos resultados. Observou-se que o baixo incentivo dos docentes e tutores para os alunos, as dificuldades de aprendizagem nessa modalidade de ensino e o pouco tempo de estudo dedicado ao curso, foram elementos preponderantes para o insucesso e a evasão.

\section{Introdução}

As Instituições Federais de Ensino Superior (IFES) experimentaram, na última década, um período de expansão quantitativa e de transformações qualitativas, representadas por um aumento significativo do número de matrículas na graduação, pelos esforços na qualificação do corpo docente e pela ampliação de cursos de pós-graduação stricto sensu. Essa expansão das IFES deve-se também à incorporação da Educação a Distância $(\mathrm{EaD})$ em várias delas.

A característica essencial da educação a distância é o envolvimento do aluno nas atividades de aprendizagem em um local onde o professor não está fisicamente presente, tendo maior flexibilidade para gerenciar seu tempo e desenvolver suas atividades acadêmicas e pessoais. $\mathrm{Na} \mathrm{EaD,} \mathrm{a} \mathrm{distância} \mathrm{física} \mathrm{é} \mathrm{superada} \mathrm{graças} \mathrm{às} \mathrm{Tecnologias} \mathrm{de}$ 
Informação e Comunicação que conectam professores, alunos e tutores fisicamente distantes [Carvalho, 2007].

Mesmo com a flexibilidade proporcionada por essa modalidade, muitos dos alunos que ingressam na EaD não conseguem chegar ao final de seus cursos [Almeida et al., 2013]. Essa desistência, denominada evasão escolar, é definida como a saída do estudante de um curso (ou do sistema de educação) sem concluí-lo com sucesso [Wilges et al., 2010]. O problema da evasão, embora não ocorra unicamente na $\mathrm{EaD}$ - sendo também uma preocupação para a educação presencial tradicional - ocorre devido a uma série de dificuldades nos âmbitos cognitivo, pedagógico e pessoal, conforme demonstra Ramos et al. (2014).

Contudo, a evasão ainda é um dos problemas que afligem as Instituições Federais de Ensino Superior no Brasil. As buscas de suas causas e soluções têm sido objeto de pesquisa de estudiosos da área educacional. Especificamente sobre evasão em cursos de $\mathrm{EaD}$, a literatura atual tem dado um enfoque mais frequente nas propostas de prevenção, visando combater esse fenômeno. Vê-se claramente que o tema é relevante porque as perdas de alunos com a evasão provocam desperdícios acadêmicos, econômicos e sociais.

Vários autores buscam causas que expliquem essa evasão. Alguns acreditam que seja pela falta de motivação do aluno: "a motivação deve estar presente nos educandos para que estes não sejam levados a abandonar o projeto do qual fazem parte" [Favero e Franco, 2006, p. 85]. A pesquisa de Jensen e Almeida (2009), por sua vez, identificou que a flexibilidade dos horários faz com que alguns alunos não se dediquem ao curso da forma que deveriam, sendo que muitos deles não realizam sequer um planejamento pessoal para cumprir com as atividades exigidas pelo curso.

O presente artigo apresenta uma análise dos principais motivos que levaram os alunos a evadir de um curso de graduação em uma Instituição Federal de Ensino Superior brasileira, na modalidade de Educação a Distância. O método aplicado para a coleta de dados foi a aplicação de questionários aos alunos evadidos e aos remanescentes do referido curso. Os dados foram submetidos a um tratamento estatístico básico, para a extração dos resultados. A aplicação foi realizada no segundo semestre de 2012, período em que surgiram os primeiros concluintes do curso.

\section{Trabalhos Relacionados}

Os problemas da evasão afetam e preocupam as instituições por diversas razões. Pinto e Mercado (2014) listam os principais motivos que levam a essa preocupação: "para o setor público, os recursos investidos sem o devido retorno; para o setor privado, importante perda de receita; para ambos os setores, fonte de ociosidade de professores, funcionários, equipamentos e, em algumas situações, espaço físico".

Wilges et al (2010) apontam como sugestão de combate à evasão, um software de sistema multiagentes que visa resgatar os desistentes, antes que a evasão ocorra. Já Favero e Franco (2006) defendem que, em um ambiente virtual, quando o educador mantém um diálogo com seus educandos, através de chats, fóruns, e-mails, textos de forma problematizadora, e outros recursos, consegue despertar o interesse dos 
educandos, além de manter uma linha de afeto, fazendo com que eles se sintam parte do processo como um todo, o que poderia também combater a evasão.

Martins et al. (2012) propõem o uso de redes bayesianas incorporadas ao sistema tutor de uma das disciplinas iniciais de um curso de graduação, para identificar potenciais alunos desistentes, alertando ao professor da disciplina sobre essas probabilidades. $\mathrm{O}$ uso de instrumentos preditivos como esses poderia funcionar como um recurso para auxiliar alunos com problemas durante o desenvolvimento do curso.

A prevenção da evasão também pode ser feita com o uso de ferramentas estatísticas, como é o caso da regressão linear multivariada. Rodrigues et al. (2013) adotam esse método na previsão de desempenho de estudantes a partir de um ambiente virtual de aprendizagem. A regressão foi considerada como uma ferramenta útil e viável para inferências sobre o desempenho dos estudantes, auxiliando também aos professores, tutores e coordenadores dos cursos a identificar possíveis alunos com problemas de aprendizagem que possam levá-los a desistência.

Todas essas abordagens apresentadas demonstram que a EaD dispõe atualmente de diversos instrumentos capazes de auxiliar no diagnóstico e prevenção da evasão, combatendo os seus efeitos indesejáveis nas IFES.

\section{Metodologia}

A pesquisa realizada nesse estudo, utilizou métodos qualitativos e quantitativos para elencar e analisar os possíveis fatores que influenciaram a evasão dos alunos no curso de bacharelado em Sistemas de Informação à distância da Universidade Federal de Alagoas, na modalidade de Educação a Distância.

A pesquisa de campo envolveu a coleta de dados a partir de consulta nos bancos de dados do Núcleo de Tecnologia da Informação (NTI) da UFAL e, principalmente, de questionários aplicados com os alunos evadidos e remanescentes. Os questionários foram respondidos por $31 \%$ dos alunos evadidos e por $62,5 \%$ dos alunos remanescentes no curso.

Os dados foram tabulados e os resultados foram obtidos por meio da aplicação dos conceitos básicos de estatística descritiva e posteriormente apresentados sob a forma de gráficos, objetivando apresentar o fenômeno estudado.

$\mathrm{Na}$ definição das amostras foram consideradas duas populações: a de alunos ativos e a de evadidos. Dos 49 alunos ingressantes no início do curso, no polo de Santana do Ipanema, apenas 8 estavam ativos no momento da pesquisa. O restante, 41 alunos, já havia evadido. Essas duas populações foram determinadas, segundo os critérios de Doane e Seward (2008) em 33 indivíduos, para a amostra dos evadidos e em 8 indivíduos, para a dos alunos ativos. Esses cálculos justificaram a aplicação do questionário na população total de cada grupo.

\section{Resultados e Discussão}

A apresentação dos resultados obtidos será feita nas duas seções seguintes: a primeira (4.1) trata dos resultados obtidos com os questionários respondidos pelos alunos ativos (ou remanescentes) no curso; a seguinte (4.2) trata dos resultados obtidos nos questionários respondidos pelos alunos evadidos. 
CBIE-LACLO 2015

Anais do XXVI Simpósio Brasileiro de Informática na Educação (SBIE 2015)

\subsection{Alunos Remanescentes}

Dos alunos que permaneceram no curso, $60 \%$ eram do sexo masculino e $40 \%$ do sexo feminino. Com relação à idade, $60 \%$ dos alunos estavam no intervalo de 21 a 26 anos e $40 \%$ na faixa dos 30 a 35 anos. O estado civil da totalidade dos alunos (100\%) entrevistados foi informado como solteiro. Dos alunos remanescentes, $80 \%$ deles trabalhavam $8 \mathrm{~h}$ por dia e o restante (20\%) informou uma jornada de trabalho de $6 \mathrm{~h}$ diárias.

Um dos itens do questionário buscou identificar a percentagem de alunos que em algum momento corriam o risco de desistência. Dos alunos pesquisados, $60 \%$ disseram que não cogitaram desistir do curso, mas $40 \%$ revelaram que já haviam considerado a desistência.

A questão seguinte, respondida apenas pelos alunos remanescentes que afirmaram ter pensado em desistir do curso (40\%), revelou que a metade desses alunos considerou a falta de tempo como principal motivo para pensar na desistência e a outra metade atribuiu esse desejo à desorganização da instituição.

Uma das questões buscou identificar a quantidade de horas semanais que os alunos dedicaram às disciplinas do curso. Para isto, foram criados intervalos de classes de acordo com as respostas obtidas, apresentadas no gráfico da Figura 1.

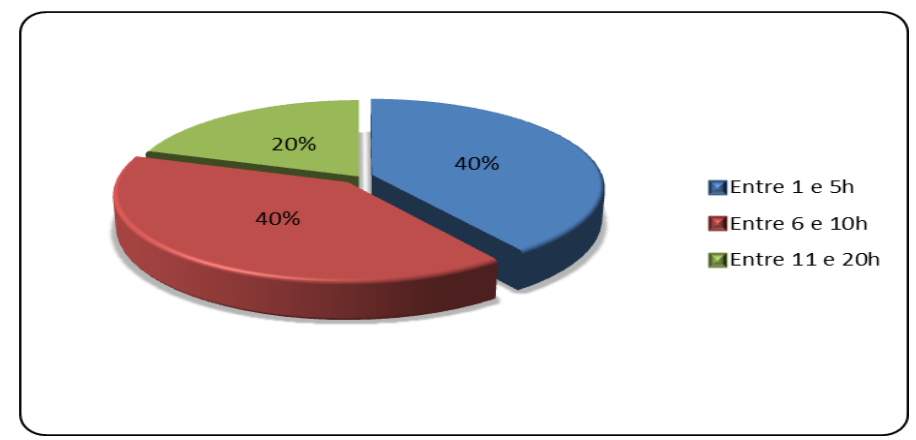

Figura 1. Horas semanais dedicadas aos estudos.

Na Figura 1, vemos que $40 \%$ dos alunos informaram que dedicavam entre $1 \mathrm{~h}$ e 5h semanais ao curso. Outros $40 \%$ afirmaram que estudavam entre $6 \mathrm{~h}$ e $10 \mathrm{~h}$ semanais e, por último, $20 \%$ dos alunos restantes, disseram que estudavam entre $11 \mathrm{~h}$ e $20 \mathrm{~h}$ semanais.

Outra questão buscava evidenciar se os alunos conseguiram desenvolver algumas habilidades estudando na modalidade de ensino $\mathrm{EaD}$, tendo em vista que tais características são essenciais para o desenvolvimento do aluno no decorrer do curso. A Figura 2 elenca os percentuais das habilidades informadas pelos alunos, desenvolvidas durante a graduação. 


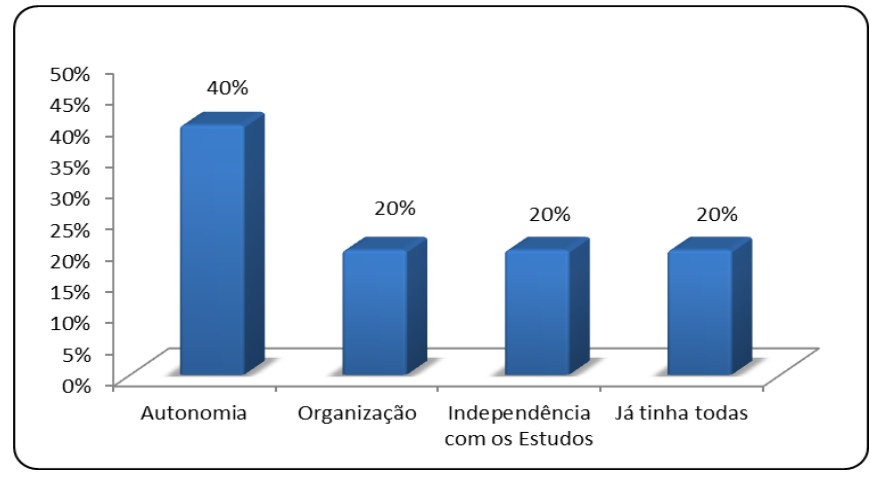

Figura 2. Habilidades que os alunos desenvolveram durante a graduação.

Segundo a Figura 2, entre as principais habilidades adquiridas no decorrer do curso, $40 \%$ dos alunos afirmaram que desenvolveram autonomia, 20\% elencaram a organização como maior virtude adquirida, $20 \%$ declararam ter desenvolvido a sua independência com os estudos e $20 \%$ dos alunos restantes responderam que já possuíam todas essas habilidades antes de ingressar na graduação.

Um dos itens do questionário abordou a avaliação dos alunos sobre o curso de Bacharelado de Sistemas de Informação da UFAL. Dos alunos respondentes, $80 \%$ consideraram o curso "Bom" e 20\% avaliaram como "Ótimo" e justificaram suas respostas afirmando que o curso traz muitas oportunidades de emprego, abrangendo um amplo mercado de trabalho.

A última questão solicitava aos alunos sugestões que pudessem ser adotadas na melhoria do curso. Nela os alunos apresentaram as seguintes propostas mais frequentes: (a) maior suporte aos alunos através de um canal direto; (b) maior contato com o professor com mais aulas presenciais; (c) maior feedback dos tutores online; e (d) maior apoio dos tutores presenciais.

\subsection{Alunos Evadidos}

Apenas $31 \%$ dos alunos evadidos pôde ser localizada para responder ao questionário. Os resultados obtidos a seguir correspondem a esse percentual dos alunos desistentes. As dificuldades de localização são maiores quando se trata de alunos residentes no interior, devido à inexistência e precariedade dos meios de comunicação em algumas localidades mais afastadas dos centros urbanos.

O questionário aplicado a essa amostra de alunos evadidos apresentava as mesmas perguntas gerais de identificação que foram usadas no questionário aplicado aos alunos remanescentes, visando formar o perfil dos entrevistados. As questões seguintes procuravam identificar os principais motivos de sua desistência.

O perfil dos alunos evadidos era composto por $54 \%$ de mulheres e $46 \%$ de homens. Entre eles, 54\% tinham idades entre 20 e 25 anos; $38 \%$ com idades entre 26 e 31 anos e $8 \%$ com idades entre 32 e 37 anos. Em relação ao estado civil, 54\% declararam-se solteiros, $32 \%$ casados e $14 \%$ disseram ser divorciados. Por fim, foi investigado se os alunos evadidos já haviam tido algum contato anterior com a Educação à Distância: apenas $8 \%$ responderam "Sim" e 92\% "Não". 
Um dos itens do questionário investigava o motivo pelo qual os alunos evadidos haviam escolhido o curso de Sistema de Informação. A Figura 3 apresenta as respostas a essa questão, em percentuais.

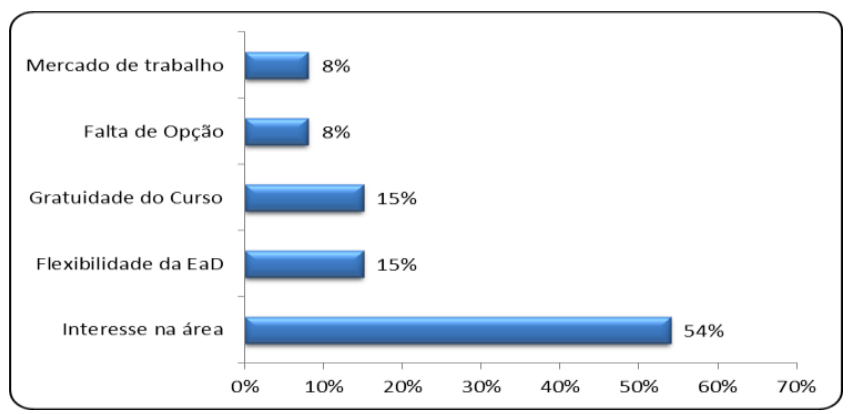

Figura 3. Principal motivo para escolha do curso.

Na Figura 3 vê-se que 54\% dos alunos alegaram que escolheram o curso, por ter interesse na área; $15 \%$ dos alunos responderam que a gratuidade do curso foi o fator decisório para a sua escolha, $15 \%$ afirmaram que optaram pelo curso devido à flexibilidade da $\mathrm{EaD}, 8 \%$ disseram que visaram o mercado de trabalho; e, por fim, $8 \%$ dos alunos admitiram que o motivo pelo qual escolheram o curso foi a falta de opção na oferta de outros cursos de graduação, na área de conhecimento desejada.

Outra questão projetada no questionário buscava identificar quantas horas semanais os alunos dedicavam ao curso, considerando-se que a $\mathrm{EaD}$ ao mesmo tempo em que dá autonomia e flexibilidade de horários também cobra retorno, em tempo hábil, das atividades desenvolvidas. A Figura 4 permite visualizar estes dados.

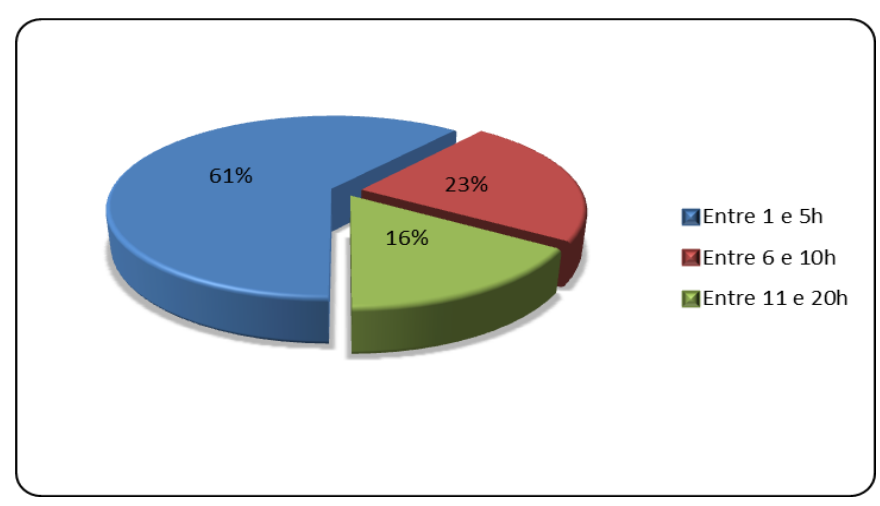

Figura 4. Horas semanais dedicadas aos estudos pelos alunos evadidos.

Os resultados da Figura 4 demonstraram que $61 \%$ dos alunos dedicavam entre $1 \mathrm{~h}$ e $5 \mathrm{~h}$ semanais ao curso, seguidos de $23 \%$ os alunos que dedicavam entre $6 \mathrm{~h}$ e $10 \mathrm{~h}$ semanais e por fim $16 \%$ dos alunos dedicavam entre $11 \mathrm{~h}$ e $20 \mathrm{~h}$ semanais.

Outra questão planejada objetivava identificar em qual período o discente abandonou o curso de graduação. Os resultados estão representados na Figura 5. 


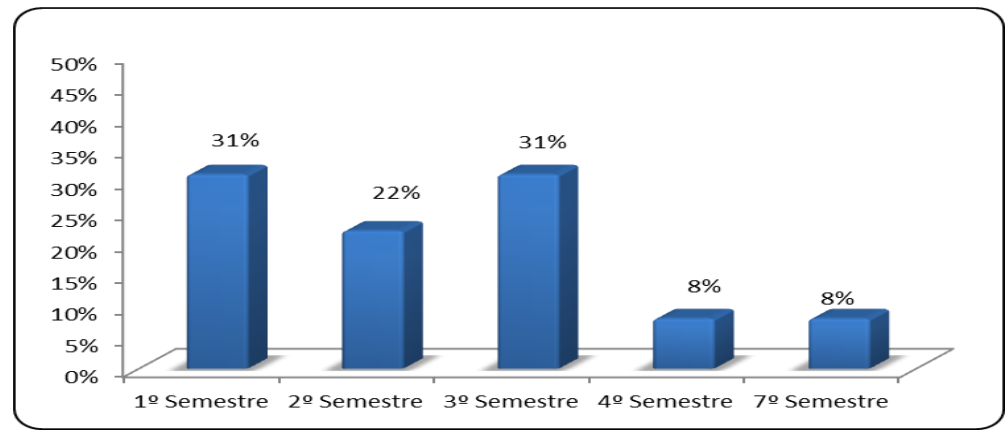

Figura 5. Evasão por semestre do curso.

Percebe-se que $31 \%$ dos alunos desistiram no primeiro semestre do curso. Isso pode ser justificado pelo "choque" do primeiro contato do aluno com a $\mathrm{EaD}$, já que $92 \%$ dos evadidos estavam tendo o seu primeiro contato com essa modalidade de ensino. $\mathrm{O}$ número de desistentes no terceiro semestre foi igual (31\%). A explicação para essa estatística pode estar associada ao fato de que nesse terceiro semestre iniciam-se justamente as disciplinas específicas da graduação e aqueles que não possuíam afinidade com o curso acabaram desistido. Por fim, 22\% dos alunos desistiram no segundo semestre, $8 \%$ desistiram no quarto semestre e os últimos $8 \%$ desistiram no sétimo semestre do curso. Percebe-se claramente que um percentual significativo dos alunos desistiu nos três primeiros semestres do curso.

Outro item do questionário tratava das atividades desempenhadas em paralelo ao curso durante a graduação. Conforme os dados obtidos, a maior parte dos alunos, além de estudar, também executava outras atividades: apenas $8 \%$ se dedicavam exclusivamente ao curso; $38 \%$ dos alunos trabalhavam 8 h por dia; $16 \%$ estudavam em outra instituição e os últimos $38 \%$ além de trabalhar entre $6 \mathrm{~h}$ e $8 \mathrm{~h}$ por dia, ainda estudavam em outra instituição de ensino.

A questão seguinte abordava diretamente o ponto central da pesquisa, ao tentar descobrir as principais causas da evasão apontadas pelos alunos. As respostas estão representadas na Figura 6.

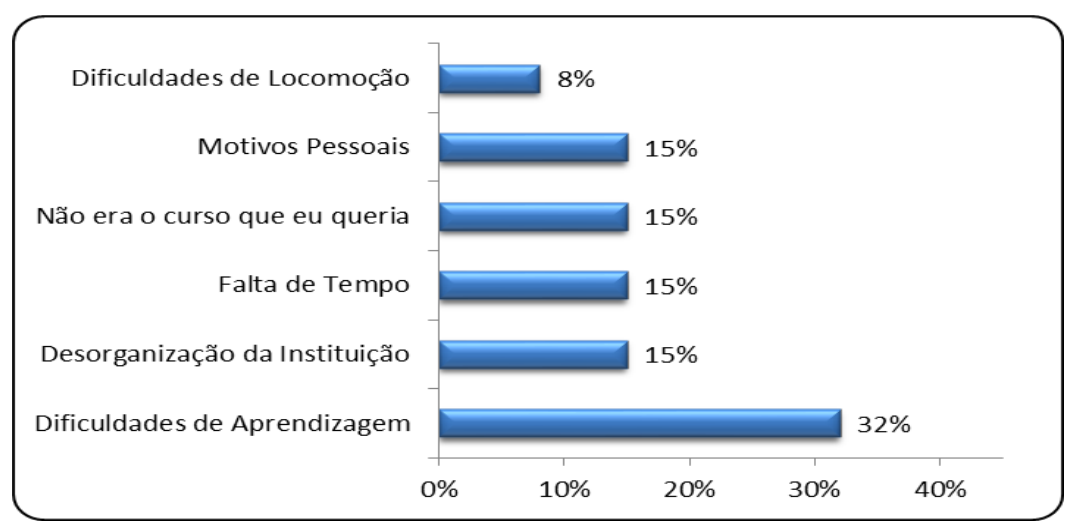

Figura 6. Motivos da evasão no curso.

A figura 6, revela os motivos de desistência entre os alunos. A resposta com menor índice percentual $(8 \%)$ correspondeu às dificuldades de locomoção e a resposta mais frequente $(32 \%)$ dizia respeito às dificuldades de aprendizagem nessa modalidade ou segundo as palavras dos próprios alunos: "não consegui me adaptar a metodologia 
da EaD". As outras respostas tiveram o mesmo percentual: $15 \%$ dos alunos alegaram ter desistido do curso por motivos pessoais, outros $15 \%$ afirmaram que não se identificavam com o curso, os seguintes $15 \%$ declararam que não dispunham de tempo suficiente para dedicar aos estudos, e os últimos $15 \%$ disseram que a desorganização da instituição foi o principal motivo do afastamento deles do curso.

Outra questão aberta projetada no questionário dos alunos evadidos, buscava contemplar as maiores dificuldades encontradas no decorrer do curso. A Figura 7 apresenta graficamente as respostas obtidas.

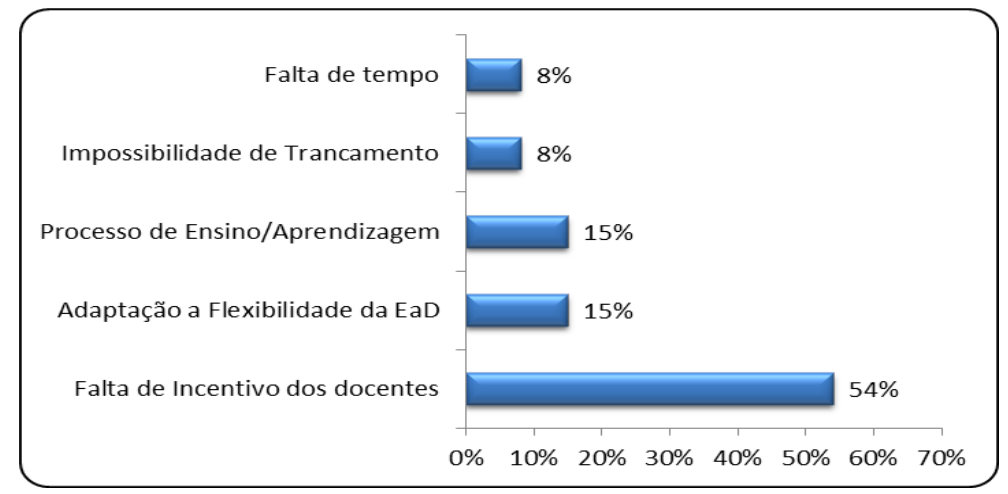

Figura 7. Dificuldades encontradas ao longo do curso.

Dos alunos evadidos, $8 \%$ alegaram que não dispunham de tempo suficiente para acompanhar as disciplinas do curso. Ainda, 15\% dos alunos afirmaram que sua maior dificuldade foi lidar com a flexibilidade da EaD. Outros $15 \%$ relataram dificuldades no processo de ensino/aprendizagem. Já $8 \%$ dos alunos afirmaram que, por motivos pessoais, desejavam trancar o curso para dar andamento posteriormente, porém devido à impossibilidade de trancamento pelas regras vigentes naquela época, só lhes restou a opção da desistência. Contudo, a falta de incentivo pelo corpo docente aos alunos foi apontada como a resposta de maior frequência e que se destaca das demais no gráfico, atingindo o patamar de $54 \%$ dos alunos entrevistados.

A última pergunta do questionário buscava investigar quais fatores poderiam ter favorecido a permanência dos alunos, impedindo a evasão. A Figura 8 exibe os fatores apontados pelos alunos evadidos entrevistados.

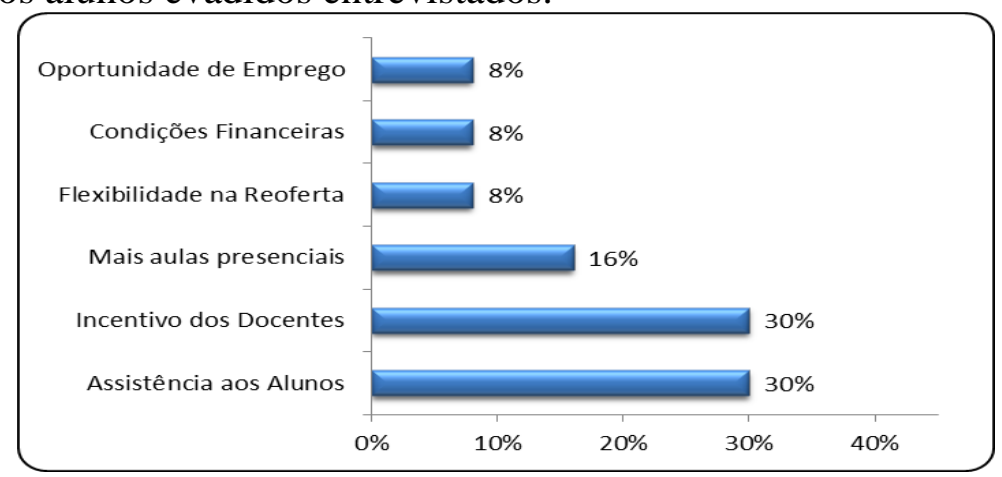

Figura 8. Fatores que poderiam ter impedido a evasão.

Dos alunos evadidos, 30\% defenderam que se houvesse maior incentivo aos alunos, por parte dos professores, provavelmente o índice de evasão seria menor. Um 
número igual de evadidos (30\%) reclamou da pouca assistência que lhe foi dada durante a graduação, afirmando que o repasse das informações referentes ao curso era deficiente. Já um percentual de $16 \%$ dos alunos acredita que o aumento do número de encontros presenciais pode ajudar na redução da evasão. Finalmente, dos alunos evadidos restantes, $8 \%$ responderam que se houvesse oportunidade de emprego dentro do estado, possivelmente eles ainda estariam frequentando o curso, outros $8 \%$ afirmaram que estavam impossibilitados de frequentar o curso devido a questões financeiras e os $8 \%$ restantes afirmaram que ficaram inadimplentes em muitas disciplinas e que se houvesse maior flexibilidade na sua reoferta, teriam a possibilidade de dar continuidade ao curso.

\section{Conclusão}

A análise dos resultados obtidos na pesquisa, mesmo tendo sido limitada a um único polo de realização do curso, pode contribuir para o aperfeiçoamento dos processos administrativos e das práticas didáticas adotadas no curso a distância investigado, à medida que identifica os seus pontos fracos e apresenta sugestões levantadas pelos próprios alunos evadidos e remanescentes. Além disso, essas descobertas podem ser úteis para fornecer pistas para estabelecer algumas estratégias de combate à evasão de futuras turmas.

Os resultados apontaram como principais fatores que motivaram a evasão, a falta de incentivo aos alunos pelo corpo docente, as dificuldades de aprendizagem e o pouco tempo dedicado aos estudos.

Outra contribuição relevante do estudo foram as sugestões apresentadas pelos alunos remanescentes para a melhoria do curso tais como: o aumento do número de aulas presenciais, a melhoria na comunicação do curso com os alunos e um maior apoio dos tutores online e presenciais.

Verificou-se também nesse estudo, que os alunos remanescentes dedicavam mais tempo as disciplinas do curso do que os alunos evadidos. Outro aspecto importante estudado foi a dificuldade de adaptação dos alunos evadidos à metodologia da $\mathrm{EaD}$, que reportaram o sentimento de abandono durante o curso.

Como a falta de incentivo dos docentes aos alunos foi considerada o principal fator desmotivador, a criação de um canal direto de comunicação entre alunos, professores e a coordenação do curso pode contribuir para a diminuição do sentimento de isolamento reportado pelos discentes e auxiliar no combate à evasão.

Apesar de o aluno na EaD possuir autonomia para executar suas atividades, ele também precisa de um incentivo maior por parte dos profissionais do curso, para que não se sinta abandonado. Para isso, é necessário que os professores da EaD estejam constantemente motivando e incentivando o alunado, para que a distância entre eles seja apenas física.

Finalizando, vale ressaltar que, apesar da evasão, a maioria dos alunos remanescentes e evadidos entrevistados na pesquisa considera o curso bom e alguns até ótimo, o que leva a crer que, caso alguns ajustes sejam realizados na organização e na metodologia adotada pelo curso, os problemas reportados pelos alunos investigados podem ser equacionados, melhorando os resultados apresentados. 
Futuros trabalhos poderão aplicar as sugestões aqui apresentadas em uma nova turma ou instituição e, posteriormente, reavaliar a evasão, pesquisando seus efeitos junto ao alunado, para verificar a efetividade das ações propostas no presente estudo. Assim, caso haja sucesso nessa iniciativa, pode-se atingir o verdadeiro objetivo desta pesquisa, que é o de contribuir para a redução da evasão e proporcionar a um contingente maior de alunos, a oportunidade de cursar uma graduação a distância em uma instituição pública e gratuita, que seja capaz de formar profissionais habilitados e competentes para enfrentar o mercado de trabalho, com novas perspectivas e visão de mundo, adquirindo as habilidades previstas nos projetos pedagógicos dos cursos projetados para essa modalidade de ensino.

\section{Referências}

Almeida, O. C. S.; Abbad, G.; Menezes, P. P. M.; Zerbini, T. (2013). Evasão em cursos a distância: fatores influenciadores. Revista Brasileira de Orientação Profissional, v. 14, p. 19-33.

Carvalho, A. B. (2007). Os Múltiplos Papéis do Professor em Educação a Distância: Uma Abordagem Centrada na Aprendizagem In: Anais do $1^{\circ}$ Encontro de Pesquisa Educacional do Norte e Nordeste, Maceió.

Doane, D. P., Seward, L. E. (2008). Estatística Aplicada à Administração e à Economia. São Paulo: McGraw-Hill.

Favero, R. V. M.; Franco, S. R. K. (2006). Um estudo sobre a permanência e a evasão na educação a distância. Revista Novas Tecnologias na Educação, v 4, n. 2.

Jensen, L. F.; Almeida, O. C. S. (2009). A Correlação entre Falta de Interatividade e Evasão em Cursos a Distância. In: Anais do $15^{\circ}$ Congresso Internacional ABED de Educação a Distância, Fortaleza.

Martins, L. C.; Lopes, D. A.; Raabe, A. (2012). Um Assistente de Predição de Evasão aplicado a uma disciplina Introdutória do curso de Ciência da Computação. In: Anais do XXIII Simpósio Brasileiro de Informática na Educação, Sociedade Brasileira de Computação, Rio de Janeiro.

Pinto, I. M. B. S.; Mercado, L. P. L. (2014). Evasão nos cursos na modalidade de educação a distância: estudo de caso do Curso Piloto de Administração da UFAL/UAB. Ensaio: aval. pol. públ. Educ., v.22, n. 83, p. 465-504.

Ramos, J. L. C.; Rodrigues, R. L.; Silva, J. C. S.; Gomes, A. S. (2014) Analisando Fatores que Afetam o Desempenho de Estudantes Iniciantes em um Curso a Distância. In: Anais do XXV Simpósio Brasileiro de Informática na Educação, Sociedade Brasileira de Computação, Dourados.

Rodrigues, R. L.; Medeiros, F. P. A.; Gomes, A. S. (2013). Modelo de Regressão Linear aplicado à previsão de desempenho de estudantes em ambiente de aprendizagem. In: Anais do XXIV Simpósio Brasileiro de Informática na Educação, Sociedade Brasileira de Computação, Campinas.

Wilges, B.; Ribas, J. C. C.; Catapan, A. H.; Bastos, R. C. (2010). Sistemas Multiagentes: mapeando a evasão na educação a distância. Revista Renote, v. 8, n. 1. 